\begin{tabular}{|c|l|}
\hline Title & Direct synthesis of alkynyI(phenyl)iodonium salts from 1-al kynes \\
\hline Author(s) & Yoshida, Masanori; Nishimura, Naoya; Hara, Shoji \\
\hline Citation & $\begin{array}{l}\text { Chemical Communications, 2002(9), 1014-1014 } \\
\text { https://doi.org/10.1039/0200659f }\end{array}$ \\
\hline Issue Date & 2002 \\
\hline Doc URL & http://hdl.handle.net/2115/36648 \\
\hline Rights & Chem. Commun., 2002, 1014- Reproduced by permission of The Royal Society of Chemistry (RSC) \\
\hline Type & article (author version) \\
\hline File Information & hara1.pdf \\
\hline
\end{tabular}

Instructions for use 


\title{
Direct synthesis of alkynyl(phenyl)iodonium salts from 1-alkynes
}

\author{
Masanori Yoshida, Naoya Nishimura, and Shoji Hara* \\ Division of Molecular Chemistry, Graduate School of Engineering, Hokkaido University, Sapporo 060-8628, \\ Japan.E-mail:hara@org-mc.eng.hokudai.ac.jp
}

\section{This submission was created using the RSC Communication template (DO NOT DELETE THIS TEXT) (LINE INCLUDED FOR SPACING ONLY - DO NOT DELETE THIS TEXT)}

\begin{abstract}
Alkynyliodonium salts can be directly prepared from 1alkynes by the reaction with iodosobenzene, tetrafluoroboric acid, and a catalytic amount of $\mathbf{H g O}$.
\end{abstract}

Alkynyl(aryl)iodonium salts have been recently used as versatile reagents for organic synthesis. ${ }^{1}$ They are generally prepared from 1-alkynes in two-steps via the corresponding 1trimethylsilyl- or 1-trialkylstannyl derivatives. ${ }^{2}$ Direct conversion of 1-alkynes to alkynyliodonium salts is more efficient and desirable, and has been studied by many chemists. ${ }^{3}$ However, the direct synthetic methods, which include the reaction of 1-alkynes with \{hydroxy(sulfonyloxy)iodo\}arenes, were applicable only for the synthesis of aryl or sterically hindered alkyl group substituted alkynyliodonium salts, and in other cases, the competitive formation of alkenyliodonium salts was a serious problem. ${ }^{3 \mathrm{a}, \mathrm{b}}$, Therefore, the two-step method has been the sole way for the synthesis of the alkynyliodonium salts with a normal alkyl group. We wish to report here the direct synthesis of 1-alkynyliodonium salts from 1-alkynes of the normal alkyl chain without the formation of the alkenyliodonium salts.

To a $\mathrm{CH}_{2} \mathrm{Cl}_{2}$ solution of iodosobenzene were added an aqueous solution of $\mathrm{HBF}_{4}$ and a catalytic amount of $\mathrm{HgO}$ to give two liquid phases, a clear organic phase and a clear yellow aqueous phase. When 1-alkyne was added to the mixture, the yellow color of the aqueous phase faded, and the formation of 1alkynyl(phenyl)iodonium salt and the absence of the 1-alkyne and the alkenyliodonium salt could be confirmed from ${ }^{1} \mathrm{HNMR}$ of the mixture. The 1-alkynyl(phenyl)iodonium salts could be isolated in good yields as $\mathrm{BF}_{4}$ salts (Scheme 1 ).

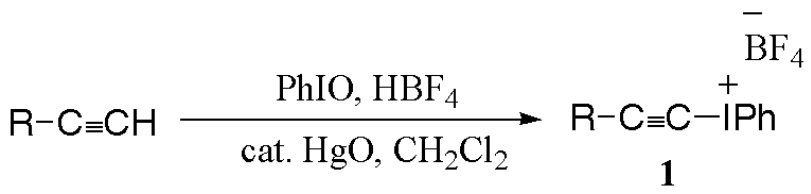

Scheme 1.

R. Caple et al. succeeded to prepare pentynyl(phenyl)iodonium tetrafluoroborate from 1-pentyne and iodosobenzene tetrafluoroborate. ${ }^{4}$ However, the synthesis of any other alkynyliodonium salts was not shown and it is a serious disadvantage of their method to use a large excess of 1-pentyne (ca. 40 times) to iodosobenzene tetrafluoroborate. According to our method, various kinds of the alkynyl(phenyl)iodonium slats can be prepared from the corresponding 1-alkynes. The alkynes having both normal alkyl group and sterically hindered one can be converted to the alkynyliodonium salts without a large excess reagents. Moreover, the introduction of functional groups such as an ester, ketone, or chloride is also possible. ( Table 1). $\dagger$ It is drawback to use a harmful mercury slat but less than $0.5 \mathrm{~mol} \%$ of $\mathrm{HgO}$ is enough to obtain the alkynyliodonium salts in good yield. It is also advantage of our method that $\mathrm{PhIO}, \mathrm{HBF}_{4}$, and $\mathrm{HgO}$ are all commercially available, while iodosobenzene tetrafluoroborate is not.

\section{Notes and references}

$\dagger$ Typical experimental procedure: $\mathrm{To}$ a $\mathrm{CH}_{2} \mathrm{Cl}_{2}$ suspension $(2 \mathrm{ml}$ ) of iodosylbenzene (132 mg, $0.6 \mathrm{mmol}$ ) were added $42 \%$ aqueous solution of $\mathrm{HBF}_{4}(7.2 \mathrm{ml}, 3 \mathrm{mmol})$ and $\mathrm{HgO}(0.54 \mathrm{mg}, 0.0025 \mathrm{mmol})$ at room temperature, and the mixture was stirred for a few minutes until the solid part dissolved completely. To the resulting mixture, 1-dodecyne (83 mg $0.5 \mathrm{mmol}$ ) was added and the mixture was stirred at room temperature until the yellow color of the aqueous phase disappeared. Then the mixture was poured into a $5 \%$ aqueous solution of $\mathrm{NaBF}_{4}(20 \mathrm{ml}, 1$ mmol) and the separated aqueous phase was extracted with $\mathrm{CH}_{2} \mathrm{Cl}_{2}$ three times. The combined organic phases were dried over $\mathrm{MgSO}_{4}$ and concentrated under reduced pressure. The product was solidified by dissolving the resulting viscous liquid in a little $\mathrm{CH}_{2} \mathrm{Cl}_{2}$, followed by the addition of a large quantity of hexane. The liquid part was removed by decantation, and the remained solid was washed with hexane. Finally, the solvent was removed completely under reduced pressure to give 1dodecynyl(phenyl)iodonium tetrafluoroborate $(173 \mathrm{mg}, 0.37 \mathrm{mmol})$. Characterization data for 1-dodecynyl(phenyl)iodonium tetrafluoroborate: white solid, M.p. $52{ }^{\circ} \mathrm{C} . \delta_{\mathrm{H}}\left(400 \mathrm{MHz}, \mathrm{CDCl}_{3}\right): 8.05$ $(2 \mathrm{H}, \mathrm{d}, J=8.1 \mathrm{~Hz}), 7.68-7.54(3 \mathrm{H}, \mathrm{m}), 1.64-1.56(2 \mathrm{H}, \mathrm{m}), 1.36-1.25$ $(16 \mathrm{H}, \mathrm{m}), 0.88(3 \mathrm{H}, \mathrm{t}, J=6.7 \mathrm{~Hz}) . \quad \delta_{\mathrm{C}}\left(100.4 \mathrm{MHz}, \mathrm{CDCl}_{3}\right): 133.82$, $132.81,132.63,114.47,114.02,31.82$, 29.47, 29.34, 29.32, 28.85, 28.73, 27.54, 22.63, 20.83, 15.86, 14.08. $v(\mathrm{KBr}) \mathrm{cm}^{-1} 2170,1057$, 739: HRMS

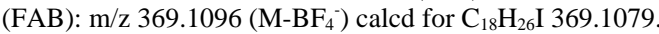

Table 1 Direct synthesis of alkynyl(phenyl)iodonium salts ${ }^{a}$

\begin{tabular}{|c|c|c|}
\hline $\mathrm{R}$ & Reaction time (min) & Yield $(\%)^{\mathrm{b}}$ \\
\hline $\mathrm{Bu}$ & 30 & 61 \\
\hline${ }^{\mathrm{t}} \mathrm{Bu}$ & 40 & 86 \\
\hline $\mathrm{C}_{10} \mathrm{H}_{21}$ & 30 & 76 \\
\hline$-\mathrm{CH}_{2}$ & 60 & 78 \\
\hline $\mathrm{Cl}-\left(\mathrm{CH}_{2}\right)_{9}$ & 30 & 80 \\
\hline${ }^{\mathrm{t}} \mathrm{BuC}(=\mathrm{O})-\left(\mathrm{CH}_{2}\right)_{9}$ & 15 & $79^{\mathrm{c}}$ \\
\hline $\mathrm{MeOOC}-\left(\mathrm{CH}_{2}\right)_{9}$ & 15 & $78^{\mathrm{c}}$ \\
\hline $\mathrm{AcO}-\left(\mathrm{CH}_{2}\right)_{9}$ & 60 & 54 \\
\hline
\end{tabular}

${ }^{a}$ The reaction was carried out as described in the note. ${ }^{\mathrm{b}}$ Isolated yield based on alkyne used. ${ }^{\mathrm{C}}$ Isolated as liquid.

1 P. J. Stang, Angew. Chem. Int. Ed. Engl., 1992, 31, 274; A. Varvoglis, The Organic Chemistry of Polycoordinated Iodine, VCH Publishers, Inc. New York, 1992, pp. 267-277; P. J. Stang, V. V. Zhdankin, Chem. Rev., 1996, 96, 1123; A. Varvoglis, Tetrahedron, 
1997, 53, 1179; M. Ochiai, Chemistry of Hypervalent Compounds, ed. K. Akiba, Wiley-VCH, New York, 1999, pp. 359-387.

2 M. Ochiai, M. Kunishima, K. Sumi, Y. Nagao, E. Fujita, M. Arimoto, and H. Yamaguchi, Tetrahedron Lett., 1985, 26, 4501; T. Kitamura and P. J. Stang, J. Org. Chem., 1988, 53, 4105; P. J. Stang A. M. Arif, and C. M. Crittell, Angew. Chem. Int. Ed. Engl., 1990, 29, 287; T. Kitamura, M. Kotani, and Y. Fujiwara, Synthesis, 1998, 1416 .

3 a) G. F. Koser, L. Rebrovic, and R. H. Wettach, J. Org. Chem., 1981, 46, 4324. b) L. Rebrovic and G. F. Koser, J. Org. Chem., 1984, 49 4700. c) P. J. Stang, B. W. Surber, Z.-C. Chen, K. A. Roberts, and A. G. Anderson, J. Am. Chem. Soc., 1987, 109, 228. d) T. Kitamura, R. Furuki, H. Taniguchi, and P. J. Stang, Tetrahedron, 1992, 48, 7149. e) A. B. Sheremetev and E. V. Mantseva, Tetrahedron Lett., 2001, 42, 5759

4 V. V. Zhdankin, R. Tykwinski, B. Berglund, M. Mullikin, R. Caple, N. S. Zefirov, and A. S. Koz'min, J. Org. Chem. 1989, 54, 2609. 